\title{
Fetal and Neonatal Responses to Maternal Canine Starvation: Circulating Fuels and Neonatal Glucose Production
}

\author{
R. M. KLIEGMAN, ${ }^{(44)}$ E. L. MIETTINEN, AND P. A. J. ADAM \\ Department of Pediatrics, Division of Pediatric Metabolism, Case Western Reserve University at Cleveland \\ Metropolitan General Hospital, and Rainbow Babies and Children's Hospital, Cleveland, Ohio, USA
}

\begin{abstract}
Summary
Pregnant dogs were starved for $72 \mathrm{hr}$ while controls were fasted overnight. Maternal starvation significantly reduced fetal birth weight $(269 \pm 7.2$ versus $294 \pm 4.4 \mathrm{~g})$. Total caloric deprivation had no effect on maternal or fetal blood glucose concentrations at the time of delivery; however, fasting neonatal blood glucose levels were depressed during the first $9 \mathrm{hr}$ of life. Starvation produced a large elevation of maternal free fatty acids $(1.68 \pm 0.39$ versus 0.74 $\pm 0.2 \mathrm{mM})$ and ketone bodies $(2.99 \pm 0.70$ versus $1.04 \pm 0.48)$. Although fetal free fatty acids increased minimally $(0.39 \pm 0.03$ versus $0.22 \pm 0.07$ ), ketone body levels were markedly elevated $(2.53 \pm 0.35$ versus $1.01 \pm 0.32)$. After birth, plasma-free fatty acid and $\beta$-hydroxybutyrate levels were lower in pups of starved mothers at $3 \mathrm{hr}$, and acetoacetate was lower at 6 and $9 \mathrm{hr}$. Other alternate fuels such as amino acids demonstrated lower levels of glutamine in pups of starved mothers throughout the day (except $3 \mathrm{hr}$ ), whereas alanine levels declined significantly only at $24 \mathrm{hr}$ (114.9 \pm 15 versus $187.6 \pm 26 \mu \mathrm{M}$.

Glucose production was significantly depressed in pups of starved mothers at $3(13.7 \pm 1.4$ versus $22.7 \pm 3)$ and $9 \mathrm{hr}(17.5$ \pm 2.2 versus $26.0 \pm 2.8 \mu$ moles $/ \mathrm{kg} / \mathrm{min}$ ), whereas glucose clearance rates were elevated at 3,6 , and 9 hr of age. Lactate carbon incorporation into glucose increased throughout the day but was not significantly affected by prior maternal starvation.
\end{abstract}

\section{Speculation}

Because glucose concentration and turnover were depressed whereas glucose clearance was elevated early during neonatal fasting, diminished oxidation of alternate fuels (such as fatty acids) may necessitate enhanced glucose consumption. Diminished intrahepatic oxidation of fatty acids may limit the energy source for sufficient glucose production from gluconeogenic precursors.

In normal adult subjects, the metabolic response to fasting follows sequential patterns of endogenous substrate mobilization and the preferential utilization by various tissues of these fuels (28). During pregnancy, there is both an augmentation and acceleration of these metabolic events. Thus, humans who are fasted during the second trimester of pregnancy have a greater and more rapid fall of glucose, alanine, and insulin concentrations (13). At the same time, maternal free fatty acids and ketone bodies increase markedly, suggesting that fatty acids have become the preferred fuel for maternal energy metabolism (20).

One mechanism which possibly relates to this accelerated response of starvation is the role which the fetus has on maternal substrates during fasting. The mother must provide a continuous supply of oxidizable fuels and precursors of fetal growth to support fetal development. During maternal starvation, the pattern of these fuels is altered as both maternal and fetal blood glucose concentrations decline while their ketone body levels become markedly elevated (16). Although there is a continuous fetal requirement for glucose, maternal provision of this substrate declines and, as in the sheep fetus, glucose utilization is depressed (36). Amino acids in the sheep or ketone bodies in other mammalian species now become increasingly important substrates which spare glucose utilization and provide a new source of fuel to support fetal energy production and possibly fetal growth (16, 36). During periods of maternal starvation, the fetus probably does not oxidize a significant quantity of free fatty acids $(23,32)$; thus, the augmented mobilization of maternal adipose tissue stores is of benefit to the mother. Partial oxidation of free fatty acids by the maternal liver produces ketone bodies which become available for utilization by fetal extrahepatic tissues (2). Simultaneously, the ongoing provision of transplacental amino acids supports the fetus with another substrate for energy production (36).

If the provision of maternal glucose to the rat fetus reaches critically low levels, the fetus may commence to mobilize its own glucose stores. Both fetal gluconeogenesis and glycogenolysis have been reported after maternal starvation (16). However, once the fetus is born and the transplacental provision of alternate fuels has ceased, the fasted neonate is obligated to continue to produce glucose. Without the presence of alternate substrates of maternal origin, the neonate must now mobilize its own fuels to provide the energy required for gluconeogenesis. Normal neonates born to alimented mothers may develop fasting hypoglycemia. In the neonatal rat, in particular, the mobilization of endogenous fuels has been shown to be insufficient to maintain blood glucose concentration and hepatic glucose production $(14,37)$. Because little is known about the effects of maternal starvation on fasting neonatal metabolism, we have investigated the effects that acute prenatal maternal canine starvation has on fetal substrate profiles and postnatal metabolic adaptation to neonatal fasting. These latter metabolic events include fuel mobilization, glucose production, lactate turnover, and lactate incorporation into glucose.

\section{MATERIALS AND METHODS}

MATERIALS

D- $\left[6-{ }^{3} \mathrm{H}\right]$ Glucose and $\mathrm{L}-\left[U_{-}{ }^{14} \mathrm{C}\right]$ lactate were purchased from New England Nuclear (Boston, MA). All enzymes were purchased from Sigma Chemical Co. (St. Louis, MO) with the exception of L-glutamate dehydrogenase which was purchased from CalBiochem, (LaJolla, CA). Scintisol was purchased from Isolab Inc. (Akron, OH).

\section{ANIMALS}

Pregnant beagles with known dates of confinement were housed in kennels and fed a standard diet consisting of Purina-Lab Canine Diet 5006 (25\% crude protein and 9\% crude fat) and Carnation Friskees Meat Flavor (9\% crude protein and 3\% crude fat) while having free access to water. 
After delivery by cesarean section at term gestation $(60 \pm 2$ days), pups were fasted and housed in an Armstrong incubator in which the temperature was maintained between $35-37^{\circ} \mathrm{C}$ and humidity was regulated at $70 \%$.

\section{EXPERIMENTAL DESIGN}

Mothers. Pregnant dogs were completely starved for $72 \mathrm{hr}$ prior to a term cesarean section and were permitted free access to water, whereas control mothers were fasted $18 \mathrm{hr}$ overnight. The latter time period was essential to prevent possible aspiration of stomach contents by the mother and to ensure accurate assessment of their duration of fasting. Immediately before surgery, intravenous anesthesia was induced with $5 \mathrm{mg} / \mathrm{kg}$ of chlorpromazine, whereas the abdominal incision site was infiltrated with $2 \%$ lidocaine. Paired blood samples were taken from the mother and immediately from the fetus after delivery.

Pups. All pups were healthy, viable pink in room air, and full term. They were immediately dried and placed in the incubator. Once stabilized, each pup was weighed and had umbilical arterial and venous catheters (Argyle, St. Louis, MO) placed atraumatically. Subsequently, they were returned to the incubator where they rested unstressed for the duration of the study. All pups were completely fasted during the neonatal study period. Pups from each litter were randomly divided into groups to be infused for 3hr periods, ending at either $3,6,9$, or $24 \mathrm{hr}$ of life, with a primed constant infusion of tracer quantities of $\left[6-{ }^{3} \mathrm{H}\right]$ glucose $(0.5 \mu \mathrm{Ci} /$ $\mathrm{kg} / \mathrm{min}$; specific activity, $33.9 \mathrm{Ci} / \mathrm{mmole})$ and $\left[U_{-}{ }^{14} \mathrm{C}\right]$ lactate $(0.5$ $\mu \mathrm{Ci} / \mathrm{kg} / \mathrm{min}$; specific activity, $138 \mathrm{mCi} / \mathrm{mmole}$ ) dissolved in sterile isotonic saline. The prime of the respective tracers was injected rapidly to provide $45 \mu \mathrm{Ci} / \mathrm{kg}$ of labeled glucose and lactate. The subsequent continuous constant infusion was delivered by previously calibrated rotary pumps. All infusions were administered by way of the umbilical venous catheter.

Blood was sampled via the umbilical arterial catheter every 30 min during a 3-hr period of infusion. An equivalent volume of normal saline was returned to replace each blood sample. Cold $10 \%$ perchloric acid (PCA) was added to the sample, which was then mixed and stored at $-80^{\circ} \mathrm{C}$ until it was analyzed for blood glucose, lactate, alanine, aspartate, glutamate, glutamine, urea concentrations, and $\left[{ }^{3} \mathrm{H}\right]$ glucose and $\left[{ }^{14} \mathrm{C}\right]$ lactate specific activities as indicated below. In addition, a final blood sample was withdrawn at the end of the infusion, replaced with saline, and centrifuged to permit the determination of plasma free fatty acids, triglycerides, and ketones after storage at $-80^{\circ} \mathrm{C}$ as described below. Due to limitations in sample size all determinations were not able to be performed on each pup.

\section{ANALYSES}

Substrates. After the PCA-precipitated blood was neutralized with $\mathrm{K}_{2} \mathrm{CO}_{3}$, glucose and lactate were assayed as reported before (1). Alanine, glutamate, and glutamine were fluorometrically determined as described in Bergmeyer (5), whereas aspartate was assayed as per Lowry and Passonneau (24).

Urea was determined on the Centrifichem with a kit purchased from Union Carbide (Rye, NY) for the spectrophotometric analysis of urea with urease to liberate $\mathrm{NH}_{3}$ which is then stoichiometrically assayed (5).

Acetoacetate was analyzed within 1 wk of storage, whereas other plasma substrates were stored for longer periods at $-80^{\circ} \mathrm{C}$. Acetoacetate and $\beta$-hydroxybutyrate were assayed fluorometrically as in Bergmeyer (5), with appropriate plasma blanks. Free fatty acids were colorimetrically determined as described by Novak (29) after extraction of plasma with Dole's mixture (11) and standardization with palmitic acid (Sigma Chemical Co.). Triglycerides were determined with a kit purchased from CalBiochem and assayed spectrophotometrically on the Centrifichem after enzymatic liberation of glycerol and subsequent analysis (5). (38).
Glucose Kinetics. Neutralized samples of PCA-treated blood were evaporated to dryness to remove ${ }^{3} \mathrm{H}_{2} \mathrm{O}$. They were reconstituted with unlabeled water. Glucose and lactate were then separated with microcolumn chromatography (Dowex AG 1-X8) (1).

Radioactivity in ${ }^{3} \mathrm{H}$ and ${ }^{14} \mathrm{C}$ was counted by liquid scintillation in the commercial fluid, Scintisol, for $10 \mathrm{~min}$ with external and internal standards. All counts were corrected for background, blanks, and quenching, as well as residual ${ }^{14} \mathrm{C}$ in the ${ }^{3} \mathrm{H}$ channel, and were expressed as disintegrations per minute.

Calculations. Glucose production was determined at each 30min time period using steady-state equations when blood glucose and specific activities were constant. Once a steady state had been achieved, the mean of the last three or four time points were reported as the mean for that pup. Under the above steady state definitions:

Glucose production ( $\mu$ moles $/ \mathrm{kg} / \mathrm{min}$ )

$$
=\text { glucose utilization }=\mathrm{F} / \mathrm{SA}
$$

where: $\mathrm{F}=$ infusion rate $(\mathrm{dpm} / \mathrm{kg} / \mathrm{min})$; and $\mathrm{SA}=$ the specific activity of substrate $(\mathrm{dpm} / \mu \mathrm{mole})$. Rarely, if these parameters were in flux (less than $5 \%$ of determinations), nonsteady state equations were used.

Glucose production $(\mu \mathrm{moles} / \mathrm{kg} / \mathrm{min})$

$$
=\mathrm{F}-\mathrm{VG}(\mathrm{dSA} / \mathrm{dt}) / \mathrm{SA}
$$

where: $\mathrm{V}=$ volume of distribution corrected for noninstantaneous mixing (34) $(0.65 \times 400 \mathrm{ml} / \mathrm{kg}) ; \mathrm{g}=$ blood glucose concentration; $\mathrm{dSA} / \mathrm{dt}=$ change in specific activity per unit time; and $\mathrm{SA}=$ mean glucose specific activity.

For the most part, the production rates calculated by either equation closely agreed with one another.

Lactate turnover was calculated using equation 1 ( $\mu$ moles $/ \mathrm{kg}$ / $\min$ ).

Lactate carbon incorporation into glucose was calculated by determining the ratio of $\left[{ }^{14} \mathrm{C}\right]$ glucose to $\left[{ }^{14} \mathrm{C}\right]$ lactate specific activities (product precursor ratio) and multiplying this ratio by the glucose production rate (expressed as $\mu$ moles $/ \mathrm{kg} / \mathrm{min}$ ). An estimate of gluconeogenesis can be made by dividing this rate by two because 2 moles of lactate will produce one mole of glucose.

Glucose clearance ( $\mathrm{ml}$ blood per $\mathrm{kg}$ per $\mathrm{min}$ ) was calculated by dividing the glucose utilization rate (glucose production) by the blood glucose concentration.

Statistical Analysis. Tabular notations were recorded as the mean \pm the standard error. Statistical analysis were performed on the Texas Instruments TI-58 portable calculator or the Hewlett Packard 9830A table top calculator. Standard programs were used for Student's $t$ test analysis of data between groups.

\section{RESULTS}

The mean weight loss of pregnant dogs after $72 \mathrm{hr}$ of starvation was $700 \mathrm{~g}$. The mothers tolerated fasting well because they remained as active as control mothers. Pups born to starved mothers weighed statistically less at birth $(269 \pm 7.2$ versus $294 \pm 4.4 \mathrm{~g})(P$ $<0.01)$. Because litter sizes were virtually identical $(6.6$ versus 6.8 pups per litter), this weight loss corresponded to a $9.1 \%$ reduction of fetal tissue mass after maternal starvation. Aside from reduced size, pups of starved mothers clinically behaved similar to control pups.

\section{BLOOD GLUCOSE AND LACTATE}

Seventy-two hr of maternal starvation had no measurable effect upon maternal or fetal blood glucose concentrations at the time of operative delivery of the pups (Table 1; Fig. 1). Within $30 \mathrm{~min}$ after birth, the blood glucose concentration began to increase in fasted control pups attaining a higher steady state level by $90 \mathrm{~min}$ of age. However, the fasting blood glucose level in pups of starved mothers failed to increase and remained significantly depressed during the first $9 \mathrm{hr}$ of life. Between 9 and $21 \mathrm{hr}$ of age, blood glucose concentrations had become statistically equivalent. 
Table 1. Fasting blood glucose and lactate

\begin{tabular}{|c|c|c|c|c|c|c|}
\hline & Mother & Fetus & $3 \mathrm{hr}$ & $6 \mathrm{hr}$ & $9 \mathrm{hr}$ & $24 \mathrm{hr}$ \\
\hline \multicolumn{7}{|l|}{ Glucose } \\
\hline $\begin{array}{l}\text { Control } \\
\text { M.C.S. }^{3}\end{array}$ & $\begin{array}{l}3.68 \pm 0.81^{1}(7)^{2} \\
3.18 \pm 0.68(6)\end{array}$ & $\begin{array}{l}3.71 \pm 1.20(5) \\
2.80 \pm 0.61(6)\end{array}$ & $\begin{array}{l}7.80 \pm 0.68(15) \\
2.50 \pm 0.46^{4}(8)\end{array}$ & $\begin{array}{l}8.32 \pm 1.08(12) \\
4.00 \pm 0.69^{4}(8)\end{array}$ & $\begin{array}{l}8.74 \pm 0.85(7) \\
2.94 \pm 0.30^{4}(5)\end{array}$ & $\begin{array}{l}7.77 \pm 0.85(9) \\
6.06 \pm 0.64(5)\end{array}$ \\
\hline \multicolumn{7}{|l|}{ Lactate } \\
\hline $\begin{array}{l}\text { Control } \\
\text { M.C.S. }\end{array}$ & $\begin{array}{l}1.54 \pm 0.41(7) \\
1.83 \pm 0.44(6)\end{array}$ & $\begin{array}{l}3.50 \pm 0.49(6) \\
3.86 \pm 0.56(6)\end{array}$ & $\begin{array}{l}1.49 \pm 0.17(15) \\
1.70 \pm 0.27(8)\end{array}$ & $\begin{array}{l}1.81 \pm 0.25(11) \\
1.86 \pm 0.33(7)\end{array}$ & $\begin{array}{l}1.63 \pm 0.16(7) \\
1.44 \pm 0.09(5)\end{array}$ & $\begin{array}{l}2.33 \pm 0.27(9) \\
1.83 \pm 0.39(6)\end{array}$ \\
\hline
\end{tabular}

${ }^{1} \mathrm{mM}$ mean \pm S.E.

${ }^{2}$ Numbers in parentheses, puppy sample size.

${ }^{3}$ M.C.S., maternal canine starvation.

${ }^{4} P<0.001$.

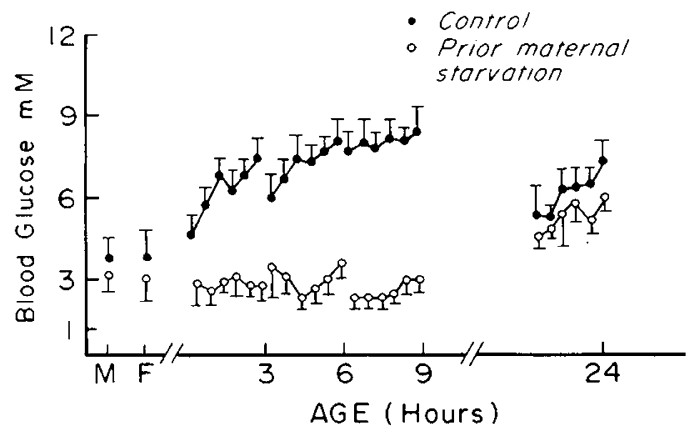

Fig. 1. Blood glucose response in mother $(M)$, fetus $(F)$, and neonate after maternal starvation (mean \pm S.E.). Numbers, puppy sample size.

As expected, blood lactate concentrations were higher in both fetal groups (Table 1). After birth, the blood lactate concentrations declined, so that by $3 \mathrm{hr}$ of age the neonatal values were one-half those in the fetus. Neither maternal starvation nor continuous neonatal fasting had an effect on blood lactate concentrations.

\section{PLASMA FREE FATTY ACIDS, TRIGLYCERIDES, AND KETONES}

In control pups, fetal free fatty acids were extremely low at the time of delivery in comparison to maternal values, but levels increased four-fold by $3 \mathrm{hr}$ of life (Fig. 2). This elevation of free fatty acids was sustained during the subsequent $24 \mathrm{hr}$ of fasting. After starvation, both maternal and fetal levels of free fatty acids were elevated. However, there was a large difference between maternal and fetal values despite mobilization of maternal adipose tissue stores. Once born, pups of starved mothers had a delayed elevation of free fatty acids as the plasma concentration achieved at $3 \mathrm{hr}$ of age was significantly lower than the control pups. However, by 6 and $9 \mathrm{hr}$ of age, there were no differences in free fatty acid levels. Nevertheless, after $24 \mathrm{hr}$ of neonatal fasting, pups born to starved mothers again had significantly lower free fatty acid concentrations as plasma levels of fatty acids declined. In contrast, control pups were able to maintain essentially the same concentrations as earlier in the fasting period.

Plasma triglyceride levels also are reported in Figure 2. Again, fetal levels were less than those in the mother at the time of delivery and increased after birth, achieving maximum concentrations at $3 \mathrm{hr}$ of age; thereafter, the levels began to decline. Maternal starvation apparently resulted in an elevation of both maternal and fetal triglyceride levels. Due to small sample sizes and large variances, these values were not significantly different. After maternal starvation, neonatal triglyceride levels were similar to those of controls at $3 \mathrm{hr}$ of age, but in contrast remained significantly elevated at $6 \mathrm{hr}$ because the concentration did not decline as in control pups. By $24 \mathrm{hr}$ of age, the triglyceride concentrations declined and were equivalent to both groups of pups.

As expected, after maternal starvation, both maternal and fetal levels of acetoacetate and $\beta$-hydroxybutyrate were increased (Fig.

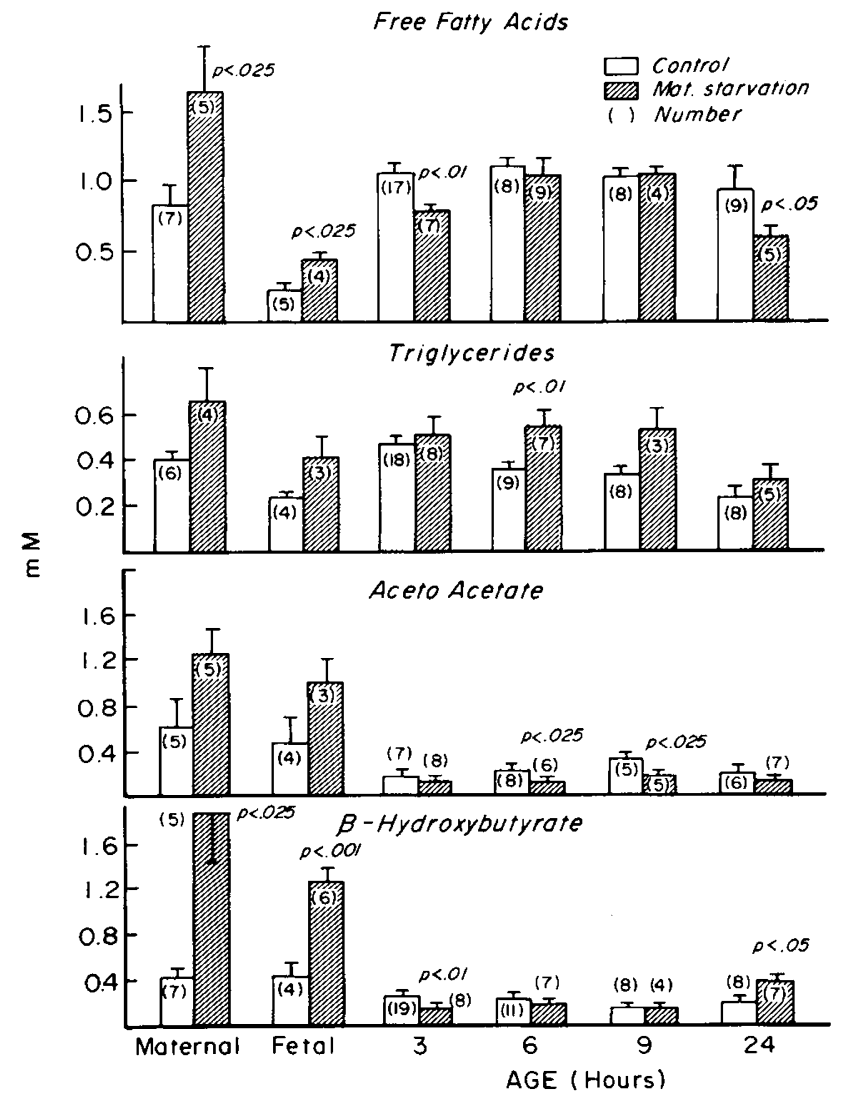

Fig. 2. Plasma free fatty acids, triglycerides, acetoacetate, and $\beta$-hydroxybutyrate (top to bottom); $\mathrm{mM}$ (mean \pm S.E.).

2). After birth, these ketones were cleared quickly as values declined rapidly and appeared to remain unchanged during neonatal fasting. However, there were differences after maternal starvation because neonatal $\beta$-hydroxybutyrate levels were lower at $3 \mathrm{hr}$ whereas acetoacetate values were lower at 6 and $9 \mathrm{hr}$ of age. At $24 \mathrm{hr}$ of age, when free fatty acid levels were lower and triglyceride concentrations had begun to decline in the pups of starved mothers, there was an elevation of $\beta$-hydroxybutyrate. This new concentration was significantly greater than the levels in 3-hr-old pups and also greater than the values of the 24-hr control pups

\section{BLOOD AMINO ACIDS}

As anticipated, fetal amino acid levels were either identical (aspartate) or higher (alanine, glutamate, and glutamine) than amino acid levels in the mother at the time of delivery (Table 2). After birth, neonatal alanine, glutamate, and glutamine levels 
Table 2. Fasting blood amino acids and urea

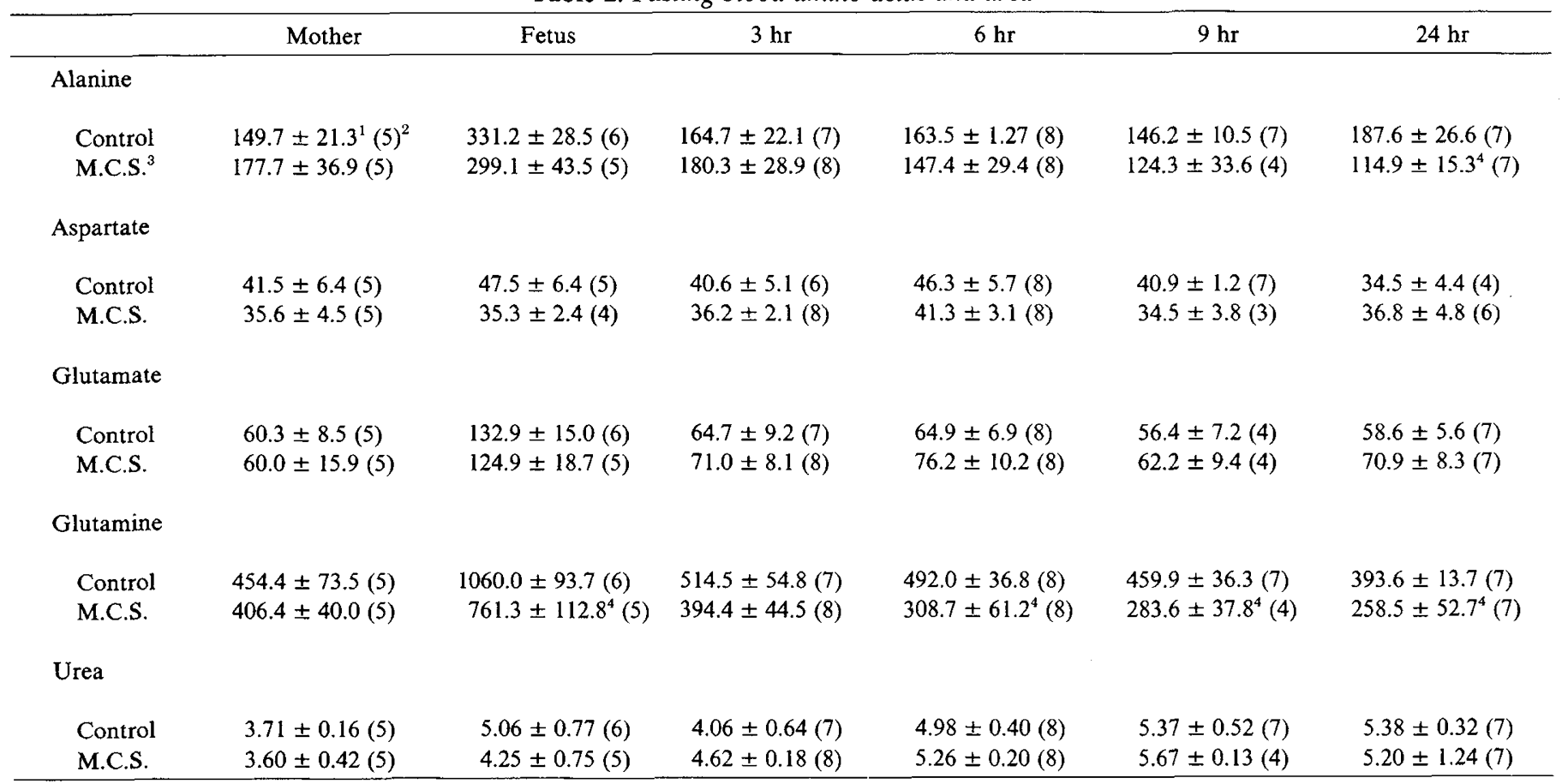

${ }^{1} \mu \mathrm{M}$ Mean \pm S.E.

${ }^{2}$ Numbers in parentheses, puppy sample size.

${ }^{3}$ M.C.S., maternal canine starvation.

${ }^{4} P<0.05$.

declined whereas aspartic acid concentrations remained unchanged throughout the first $24 \mathrm{hr}$ of life. After maternal starvation, glutamine levels were significantly lower during fetal and subsequent neonatal life (except at $3 \mathrm{hr}$ of age), whereas alanine was significantly decreased only in pups which were 24 -hr-old. Blood urea nitrogen concentrations, as expected, were higher in the fetus than the mother but remained elevated during the postnatal fast. Thus, urea concentrations do not reflect the postnatal changes or differences noted in the amino acid levels described above.

\section{NEONATAL GLUCOSE PRODUCTION AND LACTATE TURNOVER}

After birth, the normal neonatal glucose production rates stabilized between 22.6 and $26.0 \mu \mathrm{moles} / \mathrm{kg} / \mathrm{min}$ (Fig. 3). In pups of starved mothers, glucose output was significantly depressed at 3 and $9 \mathrm{hr}$, resulting in glucose production rates which were 40 and $37 \%$ lower than that in control pups. By $24 \mathrm{hr}$ of age, adaptation had occurred because both glucose and glucose production rates were equivalent to those in control pups.

Glucose clearance was constant during neonatal fasting among control pups, but it was elevated significantly at 3,6 , and $9 \mathrm{hr}$ in pups of starved mothers. By $24 \mathrm{hr}$ of age, clearance had declined to control values (Fig. 3).

Lactate turnover was constant in control pups during the first $9 \mathrm{hr}$ of life but increased significantly at $24 \mathrm{hr}(P<0.05)$ (Fig. 3). In pups of starved mothers, lactate turnover was significantly elevated at $3 \mathrm{hr}$ of age, but thereafter, no differences were noted. The increase in lactate turnover at $24 \mathrm{hr}$, however, was not significant in this group. To determine the contribution which the Cori cycle exerted upon lactate turnover muscle glycogen was assayed (Table 3). At each time interval during fetal and neonatal life, there were no differences between muscle glycogen content; however, the control group did have a statistically significant but small decline in muscle glycogen content during the 24-hr neonatal fast $(P<0.05)$, which could only contribute no more than an estimated $10 \%$ of the measured lactate turnover.

Lactate carbon incorporation into glucose is reported in Figure

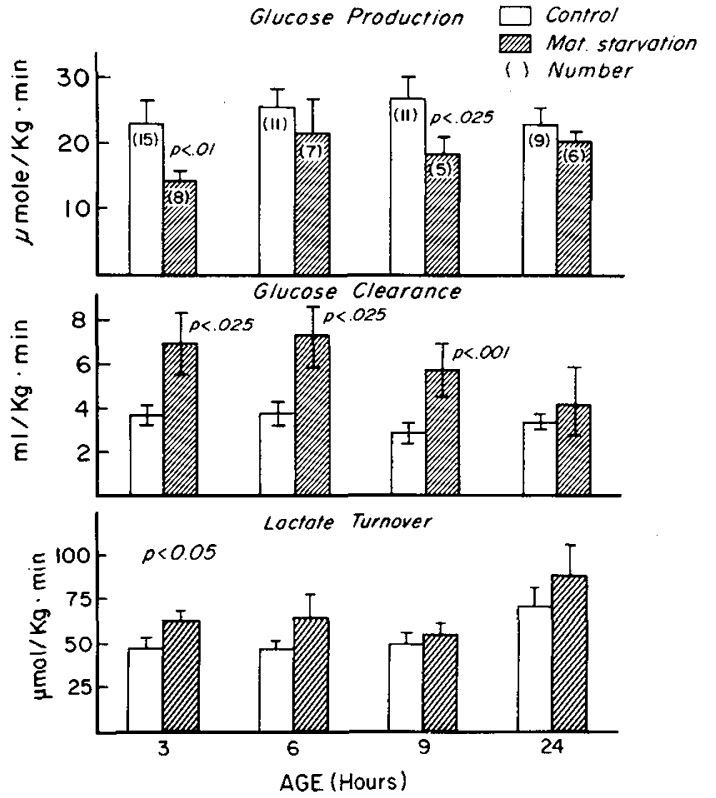

Fig. 3. Neonatal glucose production, glucose clearance, and lactate turnover rates (mean \pm S.E.).

4. There were no statistical differences between the groups at any neonatal age. However, lactate carbon incorporation increased significantly over the 24 -hr period of fasting $(P<0.05)$ and appeared to contribute more to the glucose production rate at 24 $\mathrm{hr}$ than it did at $3 \mathrm{hr}$ of age. Similarly, as seen in Figure 4, at most time periods investigated (except $24 \mathrm{hr}$ ), $\left[{ }^{14} \mathrm{C}\right]$ lactate incorporation into glucose appeared to achieve a steady-state before the end of the infusion. However, at 3 and $6 \mathrm{hr}$, the steady state level was achieved much more rapidly in pups of starved mothers because control pups had a gradual increment of ${ }^{14} \mathrm{C}$ appearance into glucose. Nine- and 24-hr-old pups from both groups now had a 
Table 3. Muscle glycogen content

\begin{tabular}{llllll}
\hline & \multicolumn{1}{c}{ Fetus } & $3 \mathrm{hr}$ & $6 \mathrm{hr}$ & $9 \mathrm{hr}$ & $24 \mathrm{hr}$ \\
\hline Control $^{3}$ & $145.3 \pm 7.4^{1}(5)^{2}$ & $139.5 \pm 10.5(7)$ & $138.8 \pm 12.3(8)$ & $118.4 \pm 5.3(7)$ & $120.1 \pm 8.8(7)$ \\
MCS $^{3}$ & $126.6 \pm 15.1(4)$ & $129.9 \pm 7.1(6)$ & $119.1 \pm 10.2(6)$ & $117.3 \pm 14.9(3)$ & $108.8 \pm 8.3(6)$ \\
\hline
\end{tabular}

${ }^{1} \mu$ moles $/ g$, mean \pm S.E.

${ }^{2}$ Numbers in parentheses, puppy sample size.

${ }^{3}$ M.C.S., maternal canine starvation.

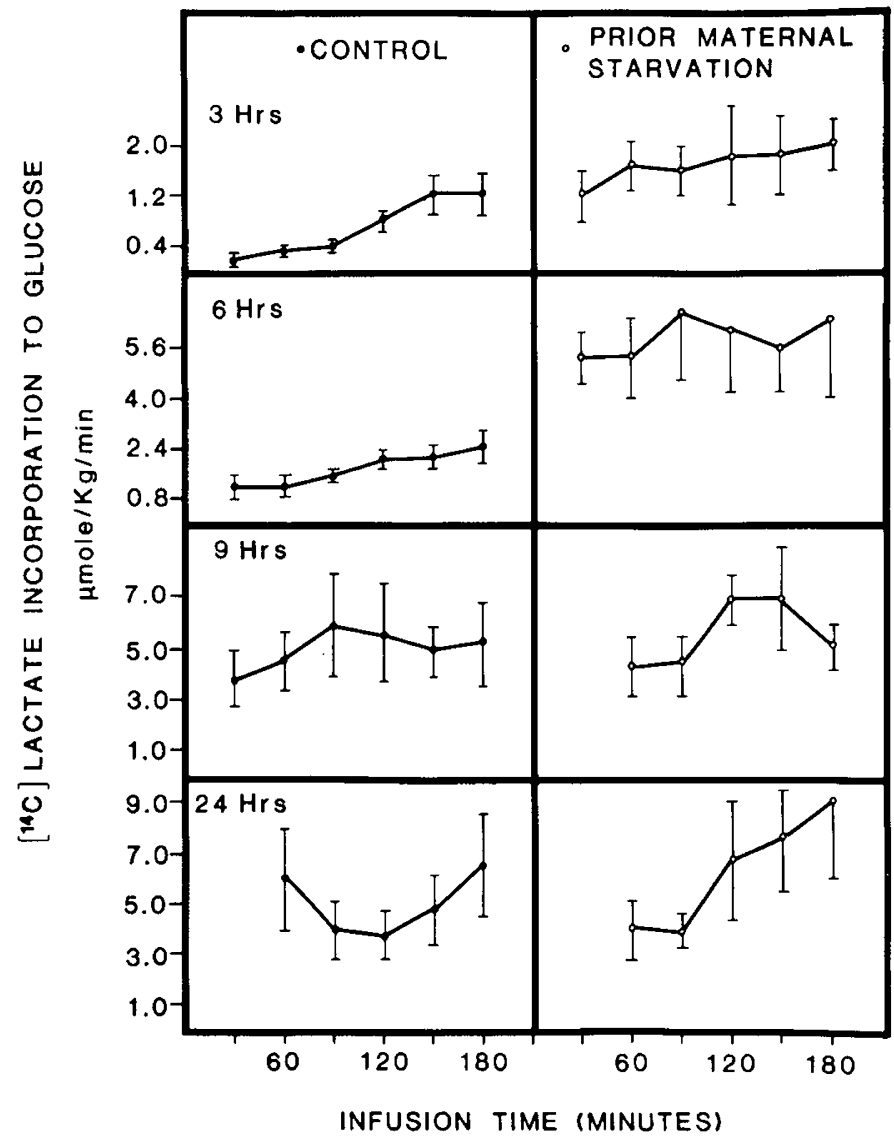

Fig. 4. Relationship of $\left[{ }^{14} \mathrm{C}\right]$ lactate carbon incorporation into glucose at $3,6,9$, and $24 \mathrm{hr}$ of age (top to bottom) to the duration of the infusion.

rapid appearance of label observed during the early points of the curve.

\section{DISCUSSION}

\section{FETAL METABOLISM}

The growth and energy metabolism of the fetus depends on continuous and sufficient transplacental provision of maternal fuels and substrates. Under conditions of adequate maternal alimentation, glucose, amino acids, and lactate may account for approximately 50,25 , and $20 \%$ of fetal ovine oxygen consumption (26). In other mammalian species, glucose may contribute a greater proportion to fetal energy production $(15,27)$.

During starvation, maternal substrate depots are mobilized and alter the pattern of fuels which are oxidized by the adult and provided for the fetus (20). Because maternal fasting rapidly lowers blood glucose concentration, alternate fuels provided by the release of free fatty acids and by their partial hepatic oxidation, i.e., ketone bodies, become important substrates oxidized by maternal and fetal tissues, respectively. In addition, during maternal starvation among sheep, the fetus will increase the oxidation of amino acids as fetal glucose utilization declines (36).

If the provision of glucose and alternate fuels is sufficient to meet fetal requirements for growth and energy metabolism, fetal weight is not significantly affected. However, if substrate supply is insufficient, body growth will be impaired, as was observed in both the present and past investigations $(16,36)$.

In the present investigation, maternal and fetal blood glucose values appeared to be unaffected at the time of delivery; however, this may be misleading. Random maternal blood glucose concentrations late in pregnancy are $5.6 \mathrm{mM}$ in well-alimented dogs. The similarity of blood glucose values in starved and control mothers (3.18 versus 3.75 ) may result from an accelerated starvation after the overnight fast to which the control mothers were subjected. For example, the decline of fetal blood glucose concentrations during maternal starvation among sheep rapidly achieves basal levels within $24 \mathrm{hr}$. Thereafter, fetal blood glucose values remain low (33). Therefore, it is possible that pups of starved mothers had low blood glucose levels during the entire period of starvation, whereas control pups were affected only during the short period of the overnight fast.

The similarity between fetal blood glucose values may also be a reflection of the initiation of fetal glucose production in utero. Isolated perfused human (3) or simian (17) fetal livers released glucose into the perfusate in the absence of circulating glucose. Fetal glucose production has also been demonstrated in the rat after maternal starvation $(16,18)$. Because our experimental design does not specifically address itself to the sources of fetal glucose, we cannot provide a direct statement concerning the specific mechanisms involved.

Fetal free fatty acids and ketone bodies at the time of delivery are increased after maternal starvation, but it is doubtful whether the small absolute elevation of free fatty acids is capable of contributing significantly to fetal energy production $(23,32)$. However, the marked rise in ketone body concentrations is very capable of supporting both energy metabolism and the synthetic requirements of selected fetal tissues. Mammalian fetal brain, in particular, is able to oxidize ketones and to incorporate these precursors into cerebral lipids, amino acids, and proteins (10, 12, 30 ). Fetal hyperketonemia in rats has been shown to increase cerebral $\beta$-hydroxybutyrate dehydrogenase, 3-oxoacid-CoA transferase, and acetoacetyl-CoA thiolase activities $(8,10)$, further supporting the potential capacity for enhanced ketone body metabolism during fetal nutritional states characterized by high fetal ketone body concentrations. In addition, after rapid and efficient diffusion across the placenta, ketones may partially spare fetal glucose utilization.

\section{NEONATAL METABOLISM}

With the cessation of the maternal-placental substrate support system, the neonate must mobilize endogenous stored fuels to provide for oxidative metabolism. Initially, glycogeneolysis supports blood glucose levels; however, as glycogen stores become limiting later in the first day, gluconeogenesis provides an important contribution. For the initiation and maintenance of gluconeogenesis, energy must be provided by the intrahepatic oxidation of alternate fuels such as free fatty acids, whereas carbon sources such as amino acids serve as precursors for net glucose production.

The normal transition from fetal to neonatal life in dogs and other mammals is accompanied by a marked elevation of free fatty acids evident at $3 \mathrm{hr}$ of life and is sustained during $24 \mathrm{hr}$ of neonatal fasting (6). In pups of starved mothers, this elevation is not as marked at $3 \mathrm{hr}$ and rises to control values at 6 and $9 \mathrm{hr}$, but 
does not persist during the entire course of neonatal fasting. This effect may be due to diminished provision or enhanced oxidation of free fatty acids in these pups. Lower levels of $\beta$-hydroxybutyrate at $3 \mathrm{hr}$ and lower levels of acetoacetate at 6 and $9 \mathrm{hr}$ suggest that hepatic partial oxidation of free fatty acids may be diminished. The cytoplasmic NAD/NADH ratio calculated from the livers of these pups shows that their redox state also suggests less neonatal hepatic fatty acid oxidation after maternal starvation $(25,31)$. Similarly, it would appear that triglyceride utilization may be impaired in pups of starved mothers because their levels are elevated before $9 \mathrm{hr}$.

Human neonates who are small for gestational age are frequently thought to have undergone some degree of intrauterine nutritional deprivation. After birth, these infants have an attenuated mobilization of free fatty acids, similar to the observation in pups of starved mothers at $3 \mathrm{hr}$ of age (9). When these neonates are given intravenous alimentation with a triglyceride emulsion, they develop hyperlipidemia, elevated free fatty acids, and a relatively attenuated ketonemia (4). The observations in pups of starved mothers and in neonates who have undergone some intrauterine caloric deprivation suggest that the utilization of fat is impaired after a period of fetal substrate insufficiency. In the early neonatal rat, hepatic fatty acid oxidation is limited by reduced mitochondrial carnitine palmityl transferase activity (23). It is possible that the proposed diminished capacity to oxidize fat in pups of starved mothers is related to reduced activity of this rate limiting enzyme. If fatty acid oxidation is impaired, glucose production from gluconeogenesis may be attenuated. Similarly, during fasting conditions, alternate substrates other than fat may have to be oxidized to support intracellular energy metabolism and to spare hepatic and peripheral tissue glucose utilization.

Amino acids have been suggested to be a potential alternate fuel during fetal and neonatal life. When maternal ovine starvation occurs, fetal urea production increases acutely so that amino acid oxidation may account for the majority of fetal oxygen consumption (36). During early neonatal fasting in rats before gluconeogenesis is active, amino acids are capable of entering oxidative pathways for energy production (7). Once hepatic gluconeogenesis is active, $25 \%$ of the amino acids derived from the diet may be oxidized elsewhere after conversion to glucose (39). In our experiment, all pups had a decline in three of four of the amino acids measured after the transition from fetal to neonatal life. This observation is noted among most mammalian species, but it does not account for the metabolic fate of these amino acids. Although there were no differences observed during early neonatal life in circulating alanine, glutamate, or aspartate concentrations, glutamine was significantly lower during fetal and most of neonatal life after maternal starvation. Although glutamine is potentially gluconeogenic, it may also be oxidized after entering the tricarboxylic acid cycle at the level of $\alpha$-ketoglutarate. During very early neonatal life, it is doubtful whether gluconeogenesis is active enough to result in a consistent reduction of glutamine levels. It is possible that glutamine enters the tricarboxylic acid cycle and is subsequently oxidized. Supportive evidence for this hypothesis evolves from the increased intrahepatic and intracerebral concentrations of $\alpha$-ketoglutarate seen at 6,9 , and $24 \mathrm{hr}$ in pups of starved mothers $(21,31)$. However, by $24 \mathrm{hr}$, blood glucose has increased to control values in pups of starved mothers whereas alanine concentrations have now declined, suggesting that gluconeogenesis has become more active during this time period. It would appear that glutamine and later alanine may be important substrates for either oxidation or gluconeogenesis in pups of starved mothers. The decline in alanine at $24 \mathrm{hr}$ may explain in part the rise of blood glucose in these pups at this time period.

\section{GLUCOSE TURNOVER}

The most striking observation after maternal starvation is the large difference between neonatal fasting blood glucose levels noted shortly after birth and persisting until $9 \mathrm{hr}$ of age. Pups of starved mothers have a relative hypoglycemia with values that are substantially lower than control pups. Between 9 and $24 \mathrm{hr}$, however, there is a period of adaptation as blood glucose levels have become equivalent by the end of the day. Glucose production is significantly lower at 3 and $9 \mathrm{hr}$ of age. However, the decline in hepatic glucose production is not as great as the depression of blood glucose levels. Because glucose clearance is markedly increased at 3,6 and $9 \mathrm{hr}$, peripheral tissues are probably extracting glucose at a greater efficiency. A further requirement for systemic glucose utilization may occur if the oxidation of alternate fuels is diminished in tissues capable of consuming substrates other than glucose. These data raise the hypothesis that if hepatic and peripheral tissue oxidation of free fatty acids were diminished so that glucose production could not increase, such an alteration would necessitate increased tissue extraction of glucose, resulting in hypoglycemia.

The precise precursor of hepatic glucose production needs to be defined and may be approximated by determining the rate of decline of hepatic glycogen concentrations. In control pups, the average decline in hepatic glycogen content between fetal and 9 $\mathrm{hr}$ of life is sufficient to produce $21 \mu \mathrm{moles} / \mathrm{kg} / \mathrm{min}$ glucose $(25$, 31 ), which is somewhat less than that measured by dilution of radioisotopically labeled glucose $(26 \mu \mathrm{moles} / \mathrm{kg} / \mathrm{min})$. The calculated hepatic glucose production from glycogen in starved pups between fetal and $9 \mathrm{hr}$ is $17.6 \mu$ moles $/ \mathrm{kg} / \mathrm{min}$ which compared favorably to that measured $(17.5 \mu \mathrm{moles} / \mathrm{kg} / \mathrm{min})$. It would appear that during early neonatal life in both groups hepatic glycogenolysis may be capable of supporting glucose production. However, from 9 to $24 \mathrm{hr}$ the average decline in hepatic glycogen content may be estimated to be only responsible for 10 and $4.5 \mu$ moles/ $\mathrm{kg} / \mathrm{min}$, respectively, in control and pups of starved mothers. During this latter period, gluconeogenesis must be operable to support hepatic glucose production, as measured glucose production rates are between 19 and $22 \mu \mathrm{moles} / \mathrm{kg} / \mathrm{min}$. Lactate carbon incorporation into glucose is initially a small component of systemic glucose production at three hr of age but increased significantly by $24 \mathrm{hr}$ where it is estimated (by turnover data) to contribute 15 to $22 \%$ of glucose production among controls and pups of starved mothers, respectively. However, differences between the measured glucose turnover and the calculated decline in hepatic glycogen content from 9 to $24 \mathrm{hr}$ suggests that gluconeogenesis may contribute a greater proportion of glucose production in controls and pups of starved mothers. This discrepancy may result from the previously reported limitations in the determination of gluconeogenesis after the incorporation of labeled precursors into glucose $(19,22)$. Although lactate turnovers were similar at all age groups except $3 \mathrm{hr}$, the measurement of the systemic appearance of lactate with a uniformly labeled lactate source may underestimate the actual lactate production rate. Similarly, the rate at which label is cycled within the tricarboxylicacid cycle and the degree of futile recycling between lactate and glucose have not been determined. Such undetermined but theoretical sources of errors may significantly affect the rate of gluconeogenesis when measured by labeled precursor incorporation into glucose.

The data in pups of starved mothers suggest that during the early hours of life glucose production is substantially derived from hepatic glycogenolysis. Later on during the day, gluconeogenesis may be initiated and begin its contribution to net hepatic glucose production. Maternal starvation, however, has no additional effect upon lactate carbon incorporation in glucose. Such results may be due to a limitation of enzymatic activities or due to a failure of alternate substrate oxidation to provide the energy for this process. Premature induction of the rate-limiting enzyme for gluconeogenesis in rat neonates has been reported after maternal starvation (16), and it is possible that this has occurred in our dogs; however, this cannot be determined by the data reported here. It is hypothesized that diminished oxidation of free fatty acids may be responsible for limited gluconeogenic activity. Evidence which may support this hypothesis may be inferred from studies of neonatal fasting among rats born to normal mothers. Glucose production in fasting neonatal rats is initially supported by glycogenolysis, 
but hepatic glucose output decreases with time, resulting in hypoglycemia if fasting continues (37). When hypoglycemic neonatal rats are given an oral feeding of triglycerides, blood glucose as well as plasma-free fatty acids and ketone bodies increase (14). Subsequently, the rise in blood glucose was not observed after inhibition of fatty acid oxidation with sodium-Pent-4-Enoate or inhibition of gluconeogenesis with 3-mercaptopicolinate. Alimentation with triglycerides significantly enhanced the conversion rate of labeled lactate and alanine to glucose, whereas the direct injection of exogenous gluconeogenic substrates produced an elevation of blood glucose concentration. Thus, in fasted neonatal rat pups (14), as in the perfused adult rat liver (40), the provision and oxidation of free fatty acids enhance the incorporation of labeled precursors and the actual rate of gluconeogenesis.

\section{CONCLUSION}

The present observations in pups of starved dogs suggest that maternal starvation has an adverse effect upon subsequent neonatal glucose and fat metabolism. The interdependent relationship between intrahepatic fatty acid oxidation and neonatal glucose production may also be altered by maternal dietary deprivation. During early neonatal life, hypoglycemic pups of starved mothers have lower free fatty acid levels, while they demonstrate enhanced glucose clearance and diminished systemic glucose production. This hypoglycemia is out of proportion to the smaller decline of glucose production rates. Glucose clearance, however, is consistantly elevated when blood glucose levels remain depressed.

\section{REFERENCES AND NOTES}

1. Adam, P. A. J., Glazer, G., and Rogoff, F.: Glucose production in the newborn dog. I. Effects of glucagon in vivo. Pediatr. Res., 9: 816 (1975).

2. Adam, P. A. J., Räihä, N., Rahiala, E-L., and Kekomäki, M.: Oxidation of glucose and $\mathrm{D}-\beta-\mathrm{OH}$ butyrate by the early human fetal brain. Acta,Pediatr. Scand., 64: 17 (1975).

3. Adam, P. A. J., Schwartz, A. L., Rahiala, E-L., and Kekomäki, M.: Glucose production in midterm human fetus. I. Autoregulation of glucose uptake. Am. J. Physiol., 234: E560 (1978).

4. Andrew, G., Chan, G., and Schiff, D.: Lipid metabolism in the neonate. J. Pediatr., 88: 273 (1976).

5. Bergmeyer, H.: Methods of enzymatic analysis. Ed. 2 (Academic Press, Inc., New York, 1974).

6. Blázquez, E., Sugase, T., Blázquez, M., and Foà, P. P.: Neonatal changes in the concentration of rat liver cyclic AMP and of serum glucose, free fatty acids, insulin, pancreatic, and total glucagon in man and in the rat. J. Lab. Clin. Med., 83: 957 (1974).

7. Cresteil, T., and Lerous, J. P.: Early postnatal metabolism of amino acids in rat. Pediatr. Res., 11: 720 (1977).

8. Dahlquist, G., Persson, U., and Persson, B.: The activity of D- $\beta$-hydroxybutyrate dehydrogenase in fetal, infant and adult rat brain and the influence of starvation. Biol. Neonate, 20: 40 (1972).

9. De Leeuw, $\mathbf{R}$ and Devris, I.: Hypoglycemia in small for dates newborn infants. Pediatrics 58: 18 (1976)

10. Devivo, D., Fishman, M., and Agrawal, H.: Preferential labeling of brain cholesterol by $\left[3-{ }^{14} \mathrm{C}\right] \mathrm{D}(-)$-3-hydroxybutyrate. Lipids, 8: 649 (1973).

11. Dole, V. P.: A relation between non-esterified fatty acids in plasma and the metabolism of glucose. J. Clin. Invest., 35: 150 (1956).

12. Edmond, J.: Ketone bodies as precursors of sterols and fatty acids in the developing rat. J. Biol. Chem., 249: 72 (1974).

13. Felig, P.: Maternal and fetal fuel homeostasis in human pregnancy. Am. J. Clin. Nutr., 26: 998 (1973)

14. Ferré, P., Pegorier, J. P., Marliss, E. B., and Girard, J. R.: Influence of exogenous fat and gluconeogenic substrates on glucose homeostasis. Am. J. Physiol., 234: E129 (1978).

15. Girard, J. R.: Metabolic fuels of the fetus. Isr. J. Med. Sci., 11: 591 (1975)

16. Girard, J. R., Ferré, P., Gilbert, M., Kervan, F., Assan, R., and Marliss, E. B.:
Fetal metabolic response to maternal fasting in the rat. Am. J. Physiol., 232: E456 (1977).

17. Glinsmann, W. H., Eisen, J. H., Lynch, A., and Chez, R. A.: Glucose regulation by isolated near term fetal monkey liver. Pediatr. Res., 9: 600 (1975).

18. Goodner, C. J., and Thompson, J. J.: Glucose metabolism in the fetus in utero: The effect of maternal fasting and glucose loading in the rat. Pediatr. Res., $l$ : 443 (1967).

19. Heath, D. F.: The redistribution of carbon label by the reactions involved in glycolysis, gluconeogenesis and the tricarboxylic acid cycle in rat liver. Biochem. J., 110: 313 (1968).

20. Kim, Y. J. and Felig, P.: Maternal and amniotic fluid substrate levels during caloric deprivation in human pregnancy. Metabolism, 21: 507 (1972).

21. Kliegman, R., Rahiala, E-L. and Adam, P.: Effects of maternal canine starvation on fetal and neonatal cerebral metabolism. Pediatr. Res. (Abstract), 13: 477 (1979).

22. Krebs, H. A., Hems, R., Weidemann, J. J., and Speake, R. N.: The fate of isotopic carbon in kidney cortex synthesizing glucose from lactate. Biochem. J., 101: 242 (1966)

23. Lockwood, E. A., and Bailey, E.: Fatty acid utilization during development of the rat. Biochem. J., 120: 49 (1970).

24. Lowry, O., and Passonneau, J.: A Flexible System of Enzymatic Analysis (Academic Press, Inc., New York, 1972)

25. Miettinen, E-L.: The effect of maternal canine starvation on fetal and neonatal liver metabolism. Am. J. Physiol., 240: $\sum 88$ (1981).

26. Milley, J. R., and Simmons, M.: Metabolic requirements for fetal growth. Clin. Perinatol., 6: 365 (1979).

27. Morris, R. H., Jr., Makowski, E. L., Meschia, G., and Battaglia, F. C.: The glucose/oxygen quotient of the term human fetus. Biol. Neonate, 25: 44 (1975)

28. Newsholme, E. A.: Carbohydrate metabolism in vivo: regulation of the blood glucose level. Clin. Endocrinol. Metab., 5: 543 (1976).

29. Novak, M.: Colorimetric ultramicro method for the determination of free fatty acids. J. Lipid Res., 6: 431 (1965).

30. Patel, M. S., and Owen, O. E.: Development and regulation of lipid synthesis from ketone bodies by rat brain. J. Neurochem., 28: 109 (1977).

31. Rahiala, E-L., Kliegman, R., and Adam, P.: Effects of maternal starvation on the intrahepatic regulation of metabolism in newborn dogs. Pediatr. Res. (Abstract), 13: 480 (1979).

32. Roux, J. F., and Myers, R. E.: In vitro metabolism of palmitic acid and glucose in the developing tissue of the rhesus monkey. Am. J. Obstet. Gynecol., 118: 385 (1974).

33. Schreiner, R. L., Nolen, P. A., Bonderman, P. W., Moorehead, H. C., Gresham, E. L., Lemons, J. A., and Escobedo, M. B.: Fetal and maternal hormonal response to starvation in the ewe. Pediatr. Res., 14: 103 (1980).

34. Searle, G. L.: The use of isotope turnover techniques in the study of carbohydrate metabolism in man. Clin. Endocrinol. Metab., 5: 783 (1976).

35. Sherman, T., and Wilson, J.: Effect of prenatally-maintained ketosis on $\beta$ hydroxybutyrate dehydrogenase and hexokinase levels in the developing rat brain. J. Neurochem., 30: 639 (1978).

36. Simmons, M. A., Meschia, G., Makowski, L., and Battaglia, F. C.: Fetal metabolic response to maternal starvation. Pediatr. Res., 8: 830 (1974).

37. Snell, K., and Walker, D. G.: Glucose metabolism in the newborn rat-temporal studies in vivo. Biochem. J., 132: 739 (1973).

38. Vannucci, R. C., and Duffy, T. E.: Influence of birth on carbohydrate and energy metabolism in rat brain. Am. J. Physiol., 226: 933 (1974).

39. White, P. K. and Miller, S. A.: Utilization of dietary amino acids for energy production in neonatal rat liver. Pediatr. Res., 10: 158 (1976).

40. Williamson, J. R., Kreisberg, R. A., and Felts, P. W.: Mechanism for the stimulation of gluconeogenesis by fatty acids in perfused rat liver. Proc. Natl. Acad. Sci. U. S. A., 56: 247 (1966).

41. Presented in part at the 1979 Society for Pediatric Research Meetings, Atlanta, Georgia

42. Dr. P. A. J. Adam had unfortunately expired prior to the publication of this investigation.

43. The authors would like to express their appreciation to George Campbell and Wendy Rolin for their technical assistance and to Dr. Sherman D. Sachs of the Department of Veterinary Medicine of Case Western Reserve University for surgical and general care of the beagles.

44. Requests for reprints should be addressed to: R. M. Kliegman, Department of Pediatrics, Bell Greve W-721, Cleveland Metropolitan General Hospital, 3395 Scranton Road, Cleveland, Ohio 44109 (USA).

45. This research was supported by NICHDD Grant HD-05740 as well as the National Foundation.

46. Received for publication May 29, 1980.

47. Accepted for publication October 20, 1980. 